East African Journal of Science, Technology and Innovation, Vol. 2 (4): September 2021

This article is licensed under a Creative Commons license, Attribution 4.0 International

(CC BY NC SA 4.0)

\title{
Impacts of reproductive and nutrition interventions on estrus and conception on Kenyan smallholder dairy farms: Reproductive trial
}

\author{
1*VANLEEUWEN J A., ${ }^{1,2}$ MURAYA J. ${ }^{2}$ GITAU G K., ${ }^{1,3}$ MAKAU D N., ${ }^{1}$ CRANE M B., \\ ${ }^{1}$ MAKENNA S L B., ${ }^{4}$ WICHTEL J J
}

1Department of Health Management, Atlantic Veterinary College, University of Prince Edward Island, Canada. ${ }^{2}$ Department of Clinical Studies, Faculty of Veterinary Medicine, University of Nairobi.

${ }^{3}$ Department of Veterinary Population Medicine, University of Minnesota, USA.

${ }^{4}$ Ontario Veterinary College, University of Guelph.

*Corresponding Author: jvanleeuwen@upei.ca

\begin{abstract}
This field trial tested the hypothesis that providing Kenyan smallholder dairy farmers with training and resources can enhance cows' cyclicity and conception using conventional or sexed semen (both types of semen have been made available in the study location by the local county government). One hundred farmers were randomly selected and randomly allocated to five equal-sized intervention groups: 1) reproduction only; 2) nutrition only; 3) reproduction and nutrition; 4) education only (quasi-control); or 5) no intervention (control). Reproductive interventions included provision of prostaglandin F2a (PG) and/or gonadotropin-releasing hormone $(\mathrm{GnRH})$ to induce estrus, and reproduction education. Nutrition interventions included provision of leguminous shrubs and nutrition education. At monthly visits over 17 months, farm and cattle data were collected, and open cattle underwent physical and reproductive exams to determine readiness for farmer decisions on sexed semen utilization. Cox proportional hazards modeling $(\mathrm{CoxPH})$ was used to determine if intervention group was significantly associated with risk of conception. The final dataset included 191 cows and 26 heifers. Lowest and highest heat submission percentages were $8.5 \%$ and $35.5 \%$ in the control and reproduction groups, respectively. Conception percentages in cows and heifers were $44.0 \%$ and $54.5 \%$ for sexed semen and $72 \%$ and $79 \%$ for conventional semen, respectively. In the final multivariable CoxPH model, each unit increase in average body condition score was associated with 3.5 times higher risk of conception. Cattle that were inseminated following spontaneous heat had 1.8 times higher risk of conception over cows that were inseminated following a hormone-induced heat. In a significant interaction variable, when cows were supplemented with a concentrate such as dairy meal in the last month of gestation (23\% of the time), a higher risk of conception was achieved in cows in groups where leguminous shrubs were fed compared to groups where no leguminous shrubs were fed. This study concludes that focused effort on improving reproduction through education, hormone use, and improved nutrition can improve heat submission and conception percentages on Kenyan smallholder dairy farms.
\end{abstract}

Keywords: Peripartum nutrition; dairy cattle; conception; semen type; hormones

Cite as: VanLeeuwen et al., (2021). Impacts of reproductive and nutrition interventions on estrus and conception on Kenyan smallholder dairy farms: Reproductive trial. East African Journal of Science, Technology and Innovation 2(4).
Received:

Accepted:

Published:

$13 / 04 / 21$

$09 / 07 / 21$

25/09/21 


\section{Introduction}

Reproductive efficiency on smallholder dairy farms (SDF) in low-income countries (LICs) is often low, as demonstrated by late sexual maturity of heifers and long calving intervals of cows (Centurión-castro et al., 2013). This situation is caused by many stressors such as heat and humidity (Khorshidi et al., 2017), diseases, parasites, poor nutrition and loss of body condition during lactation (Centurión-castro et al., 2013). Primary reproductive factors that extend calving intervals include a delay in the resumption of cycling in cows after calving, weak estrus expression, poor heat detection, poor semen quality, uterine infection, and poor timing of insemination (Kurykin, 2017).

The peri-partum period is critical to subsequent health and fertility. Minimizing the occurrence of retained fetal membranes will usually minimise the prevalence of endometritis and its effect on reproductive efficiency (Donovan et al., 2003). In early lactation, increases in milk yield after calving result in a negative-energy balance (NEB) and a decrease in body condition score (BCS) caused by mobilization of accumulated body fat (Butler, 2000). A severe NEB suppresses the luteinizing hormone (LH) pulse frequency, leading to ovarian quiescence, which extends the period from calving to first ovulation (Beam \& Butler, 1999). Negative BCS changes in early lactation lead to delayed days to first estrus as a result of delayed ovarian activity, infrequent LH pulses, poor follicular response to gonadotropins, and reduced functional competence of follicles (Chagas et al., 2007). These postpartum BCS losses can be inversely related to BCS at calving; if BCS at calving is too high, this may limit feed intake postpartum and predispose cows to a high rate of BCS loss (Wang et al., 2019). Conversely, if BCS at calving is too low, the cow will calve with limited body reserves, and in this case, BCS remains low (Wang et al., 2019). In the majority of the Kenyan smallholder cows, body condition is often low at calving and continues to be low into the postpartum period, leading to postpartum anestrus and overly long days open (Gitonga, 2010). This anestrus is also a result of inadequate quality and quantity of feeding materials, particularly during the dry season when there is unreliable feed availability (Bebe, 2004).

In LICs, various strategies have been tried to decrease the length of the calving interval, including the use of hormones to induce estrus in cows (Centurión-castro et al., 2013). Prostaglandin F2a (PG) alone requires a functional corpus luteum (CL) between days 7-16 of the estrus cycle that is lysed to induce heat in approximately three days. Alternatively, gonadotropin-releasing hormone $(\mathrm{GnRH})$ can cause ovulation of a large follicle to start a new follicular wave, and can be useful for the treatment of delayed puberty in heifers and prolonged postpartum anestrus in cows (Islam, 2011). Together, these two hormones have been used widely in high- and middle-income countries for estrus synchronization and for timed AI programs such as Ovsynch, but they are not widely used by smallholder dairy farmers in LICs (Colazo \& Mapletoft, 2014). This low use of these hormones is associated with their cost, limited availability, inconsistent availability of reliable AI services, and/or lack of awareness of the full benefits of using hormones to enhance reproductive efficiency. Appropriate nutritional management (e.g. growing high quality forages such as Calliandra - Makau et al., 2020) is essential for successful implementation of any hormone therapy programme in both cows and heifers (Islam, 2011), which can be a challenge on SDFs in LICs. Furthermore, heat detection on farms in LICs is challenging when the farm only has one adult cow, suggesting a greater potential role for hormone-induced insemination.

Sexed semen is now also available globally, and many dairy producers are using it to get larger numbers of heifer calves with high potential for future milk production. However, despite the availability of sexed semen in some LICs, its high cost per straw (Othieno, 2016) and potentially low conception percentages (Joezy-Shekalgorabi et al., 2017) have hampered its widespread use among the resource-constrained smallholder dairy farmers in sub-Saharan Africa.

A number of strategies have been promoted globally to enhance conception percentages 
when using sexed semen which would be beneficial to reduce the cost of repeat breeding. Sexed semen use is usually promoted in virgin heifers, where conception percentages with conventional semen are historically higher because intrauterine infections are much less common compared to cows (Garner \& Seidel, 2008). Since oocyte quality is a function of nutritional status (Ashworth et al., 2009), BCS may also be a factor of both conventional and sexed semen conception success. Time of insemination in relation to ovulation has been found to be critical for sexed semen, where a delay of 6 hours compared to the time used for conventional semen has been recommended (Sá Filho et al., 2010; Seidel et al., 1999). Semen companies are also trying to address other fertility factors that are under their control, including optimizing semen donor selection, sorting procedures, semen processing and handling procedures (Schenk et al., 2009), and sperm numbers per straw (Seidel \& Schenk, 2008).

To improve the reproductive performance of SDFs in LICs, additional farmer training is needed for optimizing the quality of the egg, the intrauterine environment, the detection of estrus and the timing of insemination (Richards et al., 2019). The use of sexed semen and the induction of heat by hormone therapy may also help to optimise the production of replacement heifers. However, there is limited trial research on the impacts on estrus and conception of reproductive interventions on smallholder dairy farms in countries such as Kenya, particularly when sexed semen and hormone therapy are available. This study's objectives were: 1) to assess the impact of reproductive interventions (education and hormone therapy) on inducing cyclicity and likelihood of pregnancy; 2) to determine the conception percentage of sexed semen; and 3) to determine factors associated with calving-toconception interval (CCI), all in the context of SDFs in Kenya. It was hypothesised that: the reproductive interventions will induce cyclicity and increase likelihood of pregnancy; the conception percentage for sexed semen will be lower than for regular semen; and nutritional factors will be among the key factors associated with CCI.

\section{Materials and Methods}

\section{Study area and study farms}

Approval was sought and granted from the Research Ethics Board and the Animal Care Committee of the University of Prince Edward Island, the Naari Dairy Farmers Corporative Society (NDFCS) and a partner non-profit organization, Farmers Helping Farmers. Signed consent to join and participate in the study was obtained from all the participating farmers after the project had been fully explained.

The study was carried out between August 2016 and January 2018 in the Naari sub-location of Meru County, Kenya. This study area is located in the north-eastern side of Mount Kenya and borders the Mount Kenya forest, approximately 2000 meters above sea level. Meru County has daytime high temperatures ranging from $16^{\circ} \mathrm{C}$ during the cold season (July-August) and $35^{\circ} \mathrm{C}$ in the hot season (January-February), and receives an average rainfall of between 500 to $2600 \mathrm{~mm}$ each year (worldweatheronline.com). The study area is well-suited for small-scale farming because it usually has sufficient precipitation and fertile soils, falling within the high potential agroecological zones 2 and 3 (Jaetzold \& Schmidt, 2006).

The complete list of member farmers $(n=558)$ belonging to the NDFCS was obtained, and from these farms, a list of 200 farmers was generated randomly through computer-generated random numbers for a related study (Muraya et al., 2018). The area covered by the dairy society is divided into eight regions, and sampling for the 200 farms was proportional to the number of farms in these eight areas to reflect the total number of farms per region (i.e., stratified random sample). For the current study, 100 farms from the 200 farms were then randomly selected (via computer generated random numbers), with the following inclusion criteria: they had to be currently shipping milk to the NDFCS, or currently not shipping milk to NDFCS due to all cows being dry; have three or fewer milking cows; and zero-grazing their cattle. With these inclusion criteria, we planned the study population to consist of cows having had at least one calf on semi-commercial smallholder dairy farms (semi-commercial 
because the small milking herd size meant limited milk sales compared to larger farms).

\section{Study design, intervention group definition, and sampling procedures}

The study utilised a randomised control trial design with four intervention groups of farms and one additional comparison group of farms, as described below. Random allocation of farms (via pulling group number from a hat by JM) was blocked by herd average days in milk (DIM) of lactating cows on the farms. A total of 20 farms were randomly allocated to each group at the beginning of the study. While treatment allocation was at the farm level, the unit of analysis was at the animal level. The sample size was based on a companion study (Makau et al., 2020).

\section{Intervention and control groups definition}

Cows in the first intervention group of farms (Reproduction only) received reproductive hormone treatment, where needed, and face-toface training on reproduction enhancements. Reproductive hormones were used to induce heat in DIM-eligible animals. A dose of

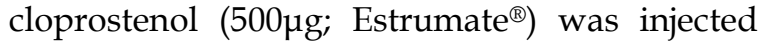
intramuscularly into cows that had a palpable corpus luteum on the day of a farm visit. A subsequent dose was given 11 days later by a locally hired technician if the cow had not come into estrus after the first dose. Cows with no palpable ovarian structures but ovaries were greater than one and a half centimeters in diameter received $100 \mu \mathrm{g}$ of gonadorelin (Fertiline ${ }^{\circledR}$ ) intramuscularly.

The second group of farms (Nutrition only) received leguminous shrubs and face-to-face training on nutritional enhancements. Two high protein leguminous fodder shrubs were used, namely Calliandra calothyrsus and Sesbania sesban (150 shrubs of each kind distributed to each farmer), which were distributed to the farmers as seedlings seven months before the trial started so that the shrubs would be mature enough to start feeding at the start of the trial. The farmers were taught how to plant and care for the shrubs, and how to harvest the leaves of the shrubs for the lactating cows as a supplement. Two types of leguminous shrubs were used since there was a large difference in altitude among the farms in the study area, and it was unclear which type of shrub would be best on the farms. Sesbania is known to be hardier at higher altitudes than Calliandra but has slightly lower protein content than Calliandra (Wambugu et al., 2006).

The third group of farms (Combined) received the reproductive and nutritional interventions, as described above. The fourth group (Education only) was an education-only comparison group that did not receive any of the resources of the nutrition or reproduction interventions (e.g., fodder shrubs or hormones) but did receive inperson education to help them with reproductive and nutritional management (a quasi-control group). All training on these four groups of farms took place on the participants' farms and was tailor-made to the needs of the particular farm, including husbandry practices for more milk production, enhanced reproduction, and better feeding practices for improved BCS of their cows, where applicable for the group allocation. To augment the face-to-face training, a smallholder dairy training manual of practical advice was issued to all the farmers in these four groups, and the training focused on relevant parts of the manual. On average, the training took approximately 10-30 minutes per visit.

The fifth group of farms (Control) was a true control group that did not receive any intervention or training or educational material of any kind during the study period. All farmers in all five groups had their animals dewormed as advised - typically twice per year. Also, all cows in all groups that had endometritis on the first monthly visit after day 25 postpartum were treated with a single dose of cephapirin benzathine uterine suspension (500mg; Metricure $^{\circledR}$ ) after day 25 postpartum.

\section{Data collection}

Farms were visited approximately monthly, and data were collected on cattle and farm management characteristics on these visits for 17 months in total. At these visits, questionnaires were administered by the research team through a face-to-face interview to collect information on cow and farm management and relevant history since the last visit. Due to the study population being smallholder dairy farms with few animals, 
most farms did not have record-keeping systems or even animal identification systems for their cattle. Each animal did have unique markings and names, allowing the researchers to collect relevant information on each animal at each visit, augmented by various receipts (e.g., for artificial insemination).

Sections of questions in the questionnaire included cow and farm demographics and management, disease status, and milk production. The questionnaires were pretested on five Kenyan SDFs not involved in the study. Animals were examined by the research team, including the normal physical exam that veterinarians would conduct on any sick animal (i.e., careful physical examination of each body system for identifiable abnormalities), rectal palpations of the ovaries (for follicles or CLs) and uterus (for pregnancy and abnormalities) by the same experienced palpator (JM), California Mastitis Tests (CMT), and body condition scores. Body condition score was estimated by using a five point scale with 0.25 increments, with 1 representing emaciated cows and 5 representing obese cows (Ferguson et al., 2006; Ferguson et al., 1994). Open cows were assessed at each visit to determine if they satisfied the following breeding criteria: 1 ) body condition score (BCS) $\geq 2.25$ on a 5-point scale; 2) 60-300 days in milk; 3) active ovaries (presence of a CL or follicle) on physical exam during farm visits; and 4) clear vulvar mucus, as observed by the farmer within the last 3 weeks (Figure 1). Thorough training of research personnel (including confirmation of agreement of BCS assessments) led to consistency of assessments among research team members. 


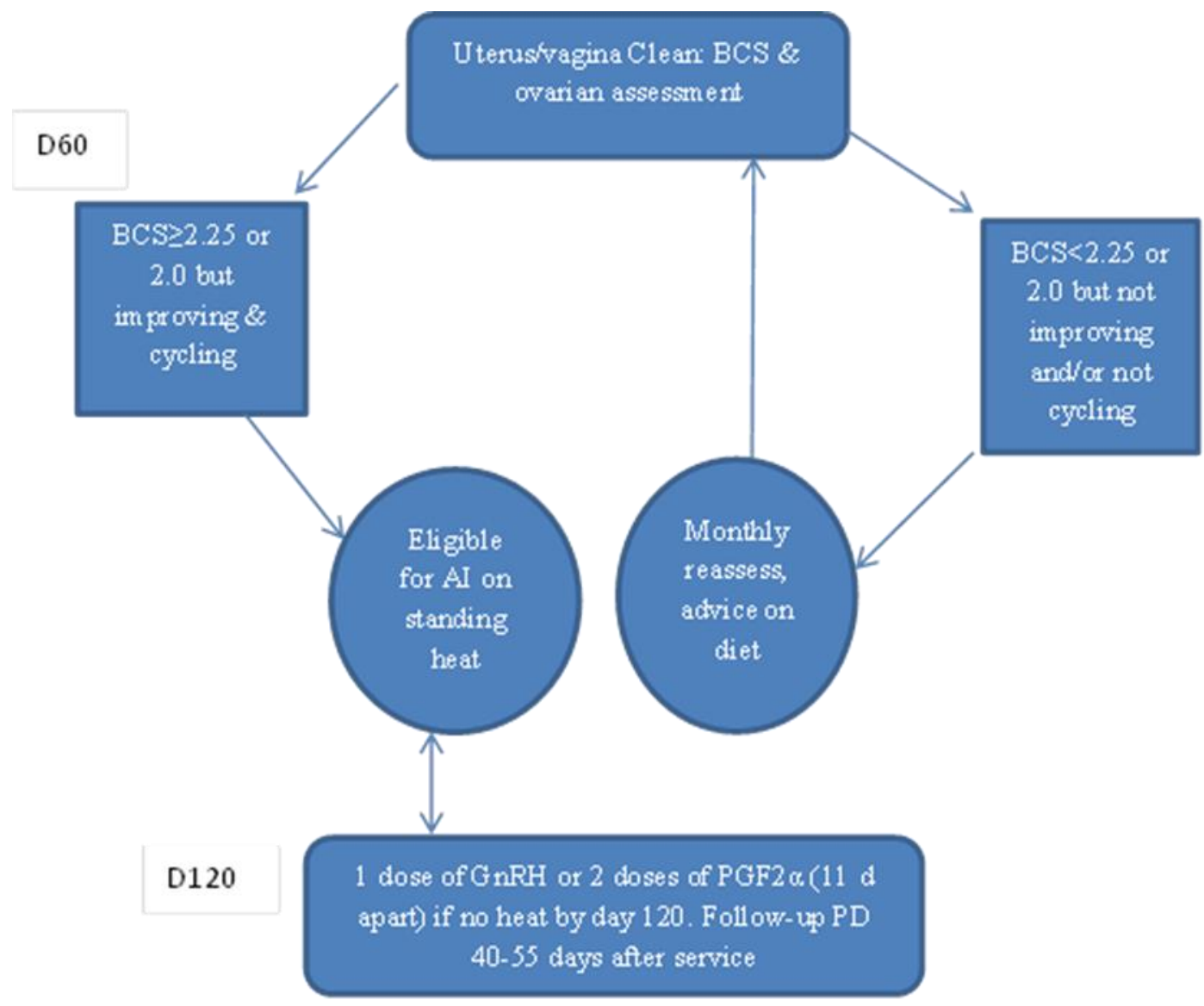

\section{If BCS not $>2.25$ by day 250 , not eligible for sexed semen. Not eligible if $>300 \mathrm{DIM}$}

Figure 1. Chart demonstrating the selection criteria for cows recruited for service using sexed semen

Open cows that met the breeding criteria were enrolled to receive up to two doses of subsidised commercial sexed semen through the NDFCS. If a cow already had two sexed semen services and was found to be still open, it was no longer eligible for more sexed semen for budgetary reasons. Insemination with conventional commercial semen through AI or a bull occurred on farms if cows failed to meet the breeding criteria for sexed semen, or if the farmer preferred to not use sexed semen, at the owner's discretion. The sexed semen cost was subsidised to be equal to the price of conventional AI semen in order to reduce the risk of farmers opting not to use sexed semen on eligible cattle. In order to have some cows bred with sexed semen that were not restricted by the breeding eligibility criteria for objective 3, farmers were given one dose of sexed semen to use on any cow during the last 3 months of the trial, regardless of the breeding criteria.

Due to lower-than-expected numbers of cows being inseminated using sexed semen during the first 11 months of the study (due to lower than normal rainfall and poor BCSs), during the last 6 months of the study, nulliparous heifers of breeding age and size were also examined for vulvar mucus, ovarian activity, and body condition score to determine if they were eligible for sexed semen (the DIM criterion was irrelevant). This additional group of cattle provided another comparison for sexed semen 
conception percentages but was not included in the CCI modeling explained below.

\section{Data management and analysis}

Field data were entered into MS Excel 2010 (Microsoft, Sacramento, California, USA). Statistical analyses were performed using Stata13.0 software (StataCorp LLC, College station, Texas, USA).

Several reproductive parameters were calculated from the dataset of cows during the 17 months of the study, and from the heifers in the last 6 months of the study. Heat submission percentage (sometimes referred to as service rate or heat detection rate) in this study was defined as the percentage of animals inseminated from all the cows that were within the DIM-eligible category of 60-300 DIM. Heat submission percentage is usually defined for a 21-day time period coinciding with the normal heat cycles of cattle. As reproductive status records were based on our reproductive assessments, and farm visits in this study did not happen every 21 days to coincide with heat cycles (for logistical reasons), the numerator for heat submission percentage was the number of animals bred since the last visit, and the denominator included the number of animals that were determined to be open during the farm visit and eligible for breeding since the last farm visit.

Conception percentage (also known as conception rate) was defined as the percentage of inseminated cows that were confirmed pregnant during a given period - in this case, one for each farm visit. Because farm visits occurred approximately monthly, the numerator for conception percentage was the number of animals confirmed pregnant during the farm visit, while the denominator included the number of animals that were bred during the relevant breeding period for those pregnancy assessments. Pregnancy percentage (also known as pregnancy rate) was defined as the product of heat submission percentage multiplied by conception percentage and was calculated for each farm visit. This modified pregnancy percentage was used for comparing the overall reproductive performance of the cows across groups.
Distributions of the variables were determined to select if parametric or nonparametric methods of analyses were appropriate. Descriptive statistics (means, s.d., medians, and/or percentages, as applicable) were calculated for the reproductive parameters and the predictor variables, including farmer demographic data, and farm and cow management data. Demographic and other known factors of conception percentage (e.g., $\mathrm{BCS}$, nutrition, uterine infection, etc.) were each examined by group comparisons to confirm the success of the random allocation at balancing these factors among groups. ANOVA was used to determine significant differences in means among the intervention groups when the continuously distributed variables were normally distributed. Mann-Whitney U-test was used to determine significant differences in median values among the intervention groups when continuously distributed variables were not normally distributed. Chi-squared test was used to determine significant differences in prevalences among the intervention groups when continuously distributed variables were categorical. ANOVA, Mann-Whitney U-test, and Chi-squared test were also used to compare each of the reproductive parameters by intervention group, where applicable, assuming that the random allocation to groups balanced out the other factors affecting the reproductive parameters between groups.

\section{Survival analysis using the outcome calving-to- conception interval}

There was a possibility that the random allocation would not balance confounding factors among the intervention groups, and therefore the following objective 3 analyses were conducted. Calving-to-conception interval (CCI) was calculated for the study cows based on the date of the most likely service preceding a positive transrectal pregnancy diagnosis. Cows that were not confirmed pregnant at the last farm visit were considered "censored" (indicating no conception yet during the study period) on that last visit date in the dataset for the analyses. A Cox proportional hazard survival analysis model was used to analyze for univariable associations $(\mathrm{P}<0.25)$ between the predictor variables and $\mathrm{CCI}$, thereby identifying factors associated with 
the hazard of conception in these data. Hazard of conception refers to the risk of conception given that the animal had not conceived up to a specific point in time. If variables had univariable associations with $\mathrm{CCI}$ at $\mathrm{P}<0.25$, they were eligible for multivariable Cox proportional hazard survival analyses, including all possible significant and confounding variables associated with CCI.

To visually understand the univariable association between BCS and CCI in the survival analysis, lowess smoothed curves were obtained since BCS was a time-varying predictor. The curve allowed us to explore the relationship between the probability of conception (by semen type) and the different body condition scores of all cows in the study on the visit prior to each service. In addition, an average BCS (adding all the scores during the breeding period and dividing by the number of scores during the breeding period) was obtained for the animals in this dataset to also explore the cumulative effect of BCS on days to conception.

Intervention group was also modified from a 5category variable to a 3-category variable (combining control and education only groups; and combining nutrition and combined intervention groups) to explore associations between CCI and other categorizations of this variable. The rationale for this re-categorization was that the two groups receiving the nutrition intervention were both expected to have an impact on BCS, and the education only and control groups were not expected to be substantially different.

Using the variables that met the $\mathrm{P}<0.25$ cut-off in the univariable survival analyses, the multivariable Cox proportional hazard survival analysis model was built using backward elimination (more robust to confounding bias), retaining any variables and two-way interactions that were significant at $\mathrm{P}<0.05$ and confounders (Dohoo et al., 2009). The final model was assessed for proportional hazards, assumption of independent censoring, overall fit of the model, functional form of the predictors, and presence of outliers and influential points in residual analyses. The Efron method was used to handle ties between two or more conception times in the model (Hertz-Picciotto and Rockhill, 1997).

\section{Results}

At the start of the study, there was a $100 \%$ response rate of the 100 farms to all invitations to participate. However, three farmers were not available for questioning on the initial visit, and the person that was left to care for the animals was not able to answer many questions; therefore, these three farms were dropped from the study. On the remaining 97 farms, there were 191 cows and 26 heifers enrolled in the study. ANOVAs showed that there were no significant differences in cow age, parity, height, weight, body condition score or pregnancy status among the groups of cows in each group, as reported elsewhere (Makau et al., 2020)

\section{Descriptive statistics}

A total of 98 and 29 cows received GnRH and PG for induction of cyclicity during the study period, respectively. Estrus was reported in 39.8\% $(39 / 98)$ of the cows that received GnRH and $58.9 \%(17 / 29)$ of the cows that received PG. From the 39 animals that displayed estrus following GnRH administration, 14 were inseminated with sexed semen and eight became pregnant resulting in a $57 \%$ conception percentage, while 22 were inseminated with conventional semen and 17 became pregnant, resulting in a $77 \%$ conception percentage. Three GnRHadministered animals showing heats were not inseminated. Out of the 17 cows that showed signs of estrus after treatment with PG, 14 were inseminated with sexed semen resulting in a $79 \%$ $(11 / 14)$ conception percentage, while three were inseminated with conventional semen, from which two became pregnant for a conception percentage of $67 \%$.

Following an intention-to-treat analysis, of the 191 cows that were enrolled in the study (Table $1)$, only 75 cows $(39.3 \%)$ were provided with sexed semen $(19.8 \%$ heat submission percentage based on eligible heats), leading to 33 conceptions (44.0\% conception percentage). Combining the heat submission percentage and conception percentage, the overall pregnancy percentage was $8.7 \%$. The range of heat submission, 
conception, and pregnancy percentages for each

of the intervention groups are shown in Table 1.

Table 1. Descriptive statistics of reproductive parameters for sexed semen use in 191 cows and 26 heifers on 97 smallholder dairy farms in Kenya in 2016-18

\begin{tabular}{llllllll}
\hline Group & Cows & Heats $^{A}$ & Inseminated & Pregnant & $\begin{array}{l}\text { Submission } \\
\text { percentage }\end{array}$ & $\begin{array}{l}\text { Conception } \\
\text { percentage }\end{array}$ & $\begin{array}{l}\text { Pregnancy } \\
\text { percentage }\end{array}$ \\
\hline Reproduction only & 43 & 110 & 39 & 14 & 35.5 & 35.9 & 12.7 \\
Nutrition only & 42 & 62 & 10 & 6 & 16.1 & 60.0 & 9.7 \\
Combined & 42 & 107 & 15 & 8 & 14.0 & 53.3 & 7.5 \\
Reproduction+Nutrition & & & & & & & \\
Education only & 36 & 52 & 7 & 3 & 13.5 & 42.8 & 5.8 \\
Control & 28 & 47 & 4 & 2 & 8.5 & 50.0 & 4.3 \\
Total & $\mathbf{1 9 1}$ & $\mathbf{3 7 8}$ & $\mathbf{7 5}$ & $\mathbf{3 3}$ & $\mathbf{1 9 . 8}$ & $\mathbf{4 4 . 0}$ & $\mathbf{8 . 7}$ \\
Heifers & 26 & 26 & 11 & 6 & 42.3 & 54.5 & 23.1 \\
\hline
\end{tabular}

APossible heats - they met the days in milk part of eligibility criteria in Figure 1

Cows in the Reproduction only group recorded the highest pregnancy percentage due to having the highest heat submission percentage $(35.5 \%)$. The other groups had heat submission percentages that were at or lower than $15 \%$ (Table 1). Cows in the Nutrition only and Nutrition and Reproduction groups had substantially higher conception percentages than the Reproduction only group. The control group had the lowest heat submission percentage and pregnancy percentage at only $8.5 \%$ and $4.3 \%$, respectively, but not the lowest conception percentage, although this percentage is based on small numbers inseminated.

Twenty-six heifers also met the breeding criteria and were enrolled for service with sexed semen during the last 6 months of the study (Table 1). Among the 26 heifers, 11 were inseminated, with six confirmed pregnant (conception percentage of $55 \%$ ). The combined conception percentage for sexed semen in the cows and heifers altogether was $50.1 \%$ (39/86). Heifers recorded a higher heat submission percentage $(42.3 \%)$ than any of the intervention group cows and a better conception percentage than all but the Nutrition only group. For comparison, the overall conception achieved by conventional semen was $72 \%$ in cows and $79 \%$ in heifers.

Thirty of the cows (16\%) had received a single dose of cephapirin for intrauterine infections during the study period. Absence of pus was subsequently reported in 23 of these cows (77\%), while two were culled due to unresolved pus in the uterus, and five had been treated for other concurrent infections, with three of the five dying and two recovering.

In the cows that were inseminated with sexed semen (75/191), a median of 205 days to conception was recorded, with a range of 56-449 days. Twelve cows had been inseminated naturally using a bull and recorded a median CCI of 270 days with a 45-774 range of CCI. The median of the CCI for the remaining cows inseminated with conventional semen (104/191) was 249 days, with a range of 29-946 days. MannWhitney U-test showed there were no significant differences in the median CCIs among these groups. There were no adverse events associated with any of the treatments related to the study. 
Univariable Cox proportional hazards model for days to conception analysis

The Cox proportional hazards survival analysis model on CCI included records from the 191 cows that were in the study. Three cow-level variables and five farm-level variables were univariably associated with $\mathrm{CCI}$ at $\mathrm{P}<0.25$ (Tables 2 and 3). The three cow-level variables included: type of semen used, whether the service was on a hormonally induced estrus, and average BCS. The five farm-level variables included: concentrate fed during the last month of gestation, farmer owned a smart phone, farmer attended dairy training, acres of land owned, and percent of land used to grow fodder. Factors not found to meet this $\mathrm{P}<0.25$ threshold included: parity, insemination attempt, and season.

Table 2. Descriptive statistics of categorical variables eligible $(P<0.25)$ to be included in the multivariable Cox proportional hazards model of days to conception for 191 cows on 97 smallholder dairy farms in Kenya in 2016-18

\begin{tabular}{|c|c|c|c|c|}
\hline Categorical Variable & Count & $\begin{array}{l}\text { Proportion } \\
\text { (\%) }\end{array}$ & $\begin{array}{l}\text { Median DIM } \\
\text { at conception }\end{array}$ & P value \\
\hline Type of semen used & & & & $0.0240^{C}$ \\
\hline - Conventional semen AI & 136 & 71.2 & 249 & Baseline \\
\hline - $\quad$ Sexed semen AI & 43 & 25.1 & 203 & 0.013 \\
\hline - $\quad$ Bulls & 12 & 7.2 & 190 & 0.405 \\
\hline \multicolumn{5}{|l|}{ Hormonally induced estrus } \\
\hline - No & 135 & 70.6 & 215 & Baseline \\
\hline - $\quad$ Yes & 56 & 29.3 & 278 & 0.099 \\
\hline \multicolumn{5}{|l|}{ Concentrate fed in last month of gestation ${ }^{B}$} \\
\hline - No & 147 & 77.0 & 246 & Baseline \\
\hline - Yes & 44 & 23.0 & 215 & 0.167 \\
\hline \multicolumn{5}{|l|}{ Farmer owned a smartphone ${ }^{B}$} \\
\hline - No & 176 & 92.1 & 228 & Baseline \\
\hline - $\quad$ Yes & 15 & 7.85 & 243 & 0.211 \\
\hline \multicolumn{5}{|l|}{ Farmer attended dairy training ${ }^{B}$} \\
\hline - No & 47 & 92.8 & 254 & Baseline \\
\hline - $\quad$ Yes & 144 & 7.2 & 216 & 0.137 \\
\hline Intervention group & & & & $0.475^{C}$ \\
\hline - $\quad$ Reproduction only & 43 & 22.5 & 261 & Baseline \\
\hline - Nutrition only & 42 & 22.0 & 215 & 0.227 \\
\hline - Reproduction \& Nutrition (Combined) & 42 & 22.0 & 222 & 0.596 \\
\hline - Education only & 36 & 18.8 & 195 & 0.248 \\
\hline - Control & 28 & 14.7 & 277 & 0.631 \\
\hline Intervention group (re-categorized) & & & & $0.604^{C}$ \\
\hline - Reproduction only & 43 & 22.5 & 261 & Baseline \\
\hline - Nutrition only and Combined & 84 & 44.0 & 222 & 0.325 \\
\hline - Education only and Control & 64 & 33.5 & 246 & 0.655 \\
\hline
\end{tabular}

Descriptive statistics of the categorical variables univariably associated with days to conception are shown in Table 2, along with the P-values for the univariable associations with days to conception. Summarization of some of these variables is provided here to add contextual information to the farms and cows in the study. Intervention group was not associated with CCI as a 5-category and a 3-category variable. 
Almost a third of the cows had not come into estrus until after induction using hormones and these cows recorded a median CCI 63 days longer than the cows coming into heat spontaneously. A quarter of the cows were supplemented with dairy meal in the last month of gestation, but their median DIM at conception was 31 days earlier than cows on farms that did not provide dairy meal in the last month of gestation. Less than $10 \%$ of the cows were owned by farmers using a smartphone (as a proxy for socioeconomic status) but those cows had higher DIM at conception. A majority of the cows were owned by farmers who had attended dairyrelated training other than what was offered by the research teams during the farm visits, and their median DIM at conception was 38 days earlier than cows owned by farmers who had not attended dairy-related training.

Descriptive statistics of the continuous variables univariably associated with days to conception are shown in Table 3, along with the P-values for the univariable associations with days to conception. The mean land holdings in this area were small, with most farmers having less than 2 acres of land (Table 3). The farmers indicated that, on average, nearly half of the land they owned was being used for growing fodder for their dairy cows. The average body condition score for the cows during the breeding period was 2.3, indicating that the study cows were generally in poor body condition

Table 3. Descriptive statistics of continuous variables eligible $(P<0.25)$ to be included in the multivariable Cox proportional hazards model of days to conception for 191 cows on 97 smallholder dairy farms in Kenya in 2016-18

\begin{tabular}{lcccc}
\hline Variable & Mean & Range & $\mathbf{9 5 \%}$ CI & P value \\
\hline Land owned (acres) & 1.86 & $0.25-21.0$ & $1.50-2.14$ & 0.065 \\
Percent land used to grow fodder & 46.6 & $20.0-95.0$ & $43.6-49.6$ & 0.182 \\
Average Body Condition Score & 2.32 & $1.33-3.54$ & $2.27-2.37$ & $<0.001$ \\
\hline
\end{tabular}

The prediction of conception (using a lowess curve) for services with sexed semen, conventional semen, and all semen according to different body condition scores at the farm visit prior to service are shown in Figure 2. A gradual increase in the probability of conception of cows was observed between BCS 1.75 to 3.5 with sexed semen and all semen (top two plots). With sexed semen, the BCS needed to be at least 2.5 to achieve a $50 \%$ probability of conception. A threshold was observed for conventional semen service around BCS 3.0, but there were not many cows inseminated with conventional semen for BCS over 3.5. 

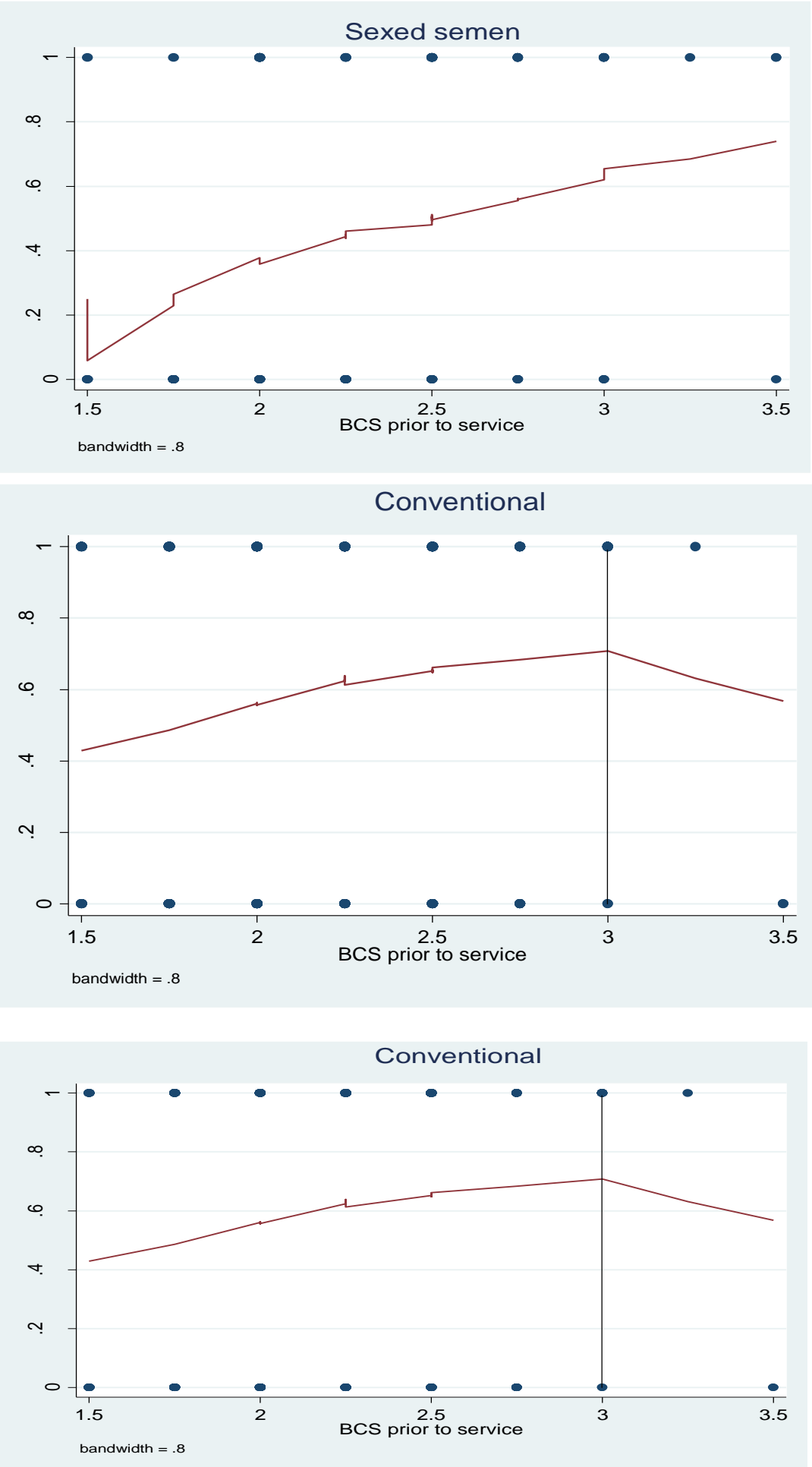

Figure 2. Prediction of probability of conception with Sexed and Conventional Semen (top left), Sexed Semen only (top right) and Conventional Semen only (bottom) with respect to the Body Condition Score (BCS) just prior to the service of cows in smallholder dairy farms in Kenya 2016-18. 
Final multivariable Cox proportional hazards model for days to conception

In the final multivariable Cox proportional hazards survival analysis model, three cow-level and three farm-level variables were significantly associated $(\mathrm{P}<0.05)$ with days to conception, and two of these variables formed an important interaction in the final model (Table 4). A one unit increase in the average BCS of cows led to a 3.5 times higher hazard of conception (hazard ratio
= 3.5). In a Cox proportional hazards survival analysis model, this hazard ratio of 3.5 is the ratio of the hazard risk corresponding to the average BCS and the hazard risk for one unit higher than the average BCS. The hazard risk in our model was the risk of conception given that the animal had not conceived up to that specific time; therefore, the hazard ratio interpretation relates to the risk of conception, adjusted for days from calving to conception.

Table 4. Final Cox proportional hazards model of calving-to-conception interval (measured in days) for 191 cows on 97 smallholder dairy farms in Kenya in 2016-18

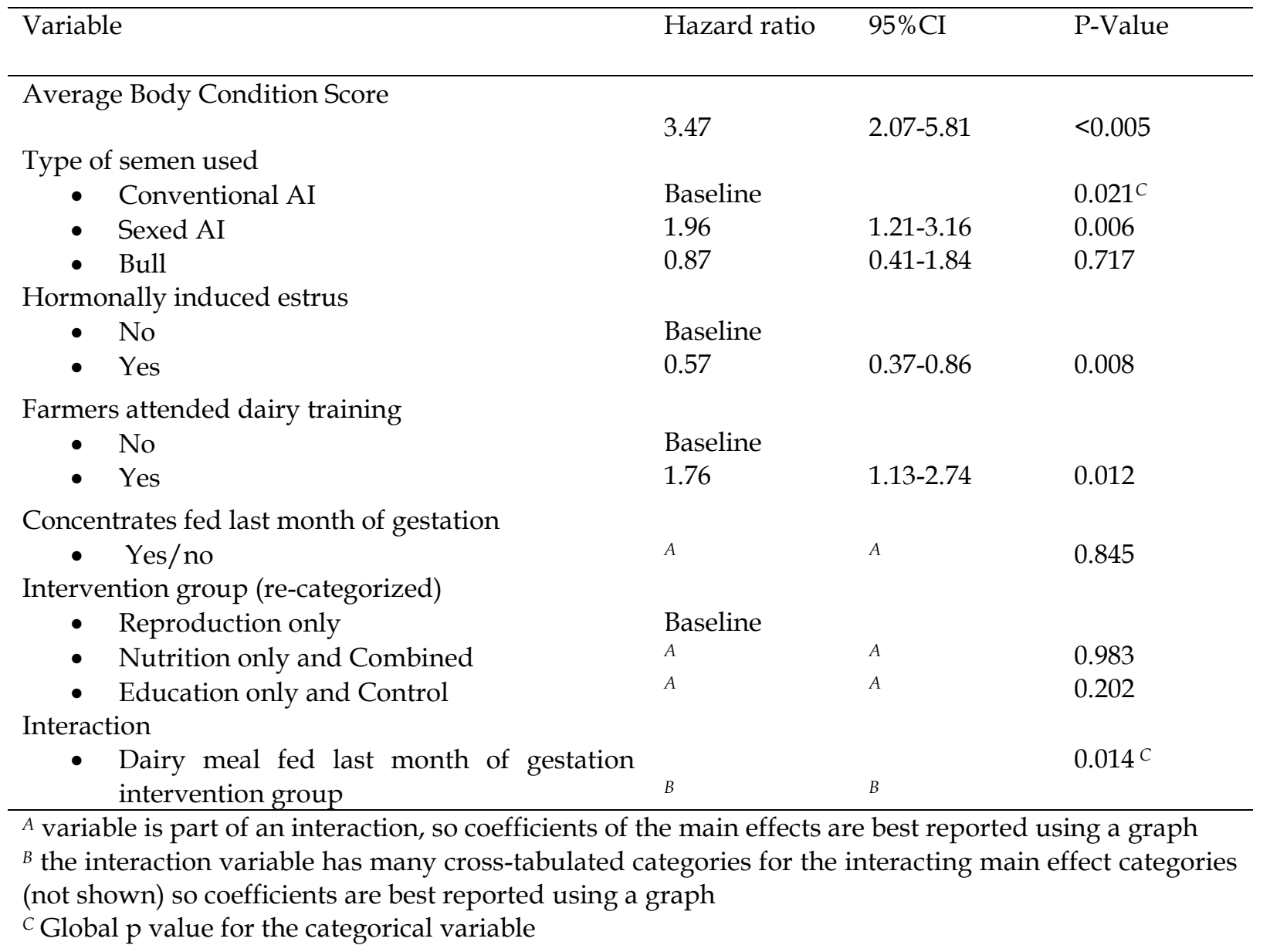

Use of sexed semen was also in the final multivariable Cox proportional hazards model, and it increased the hazard of conception by nearly 2.0 times over that of conventional semen use, while use of a bull for service had a nonsignificantly lower hazard of conception compared to conventional semen. Cows that were inseminated during a hormonally induced estrus had decreased hazard of conception for that service compared to cows that came into heat spontaneously (inverse of 0.57 is 1.8- showing a hazard risk of conception for spontaneous heats of nearly twice that of induced heats). Cows on farms where the farmers indicated having attended dairy training other than that offered by the research team had a 1.8 times higher hazard 
risk of conception compared to cows on farms where farmers reported no former dairy-related training.

The re-categorised intervention group was retained in the final model because it had a confounding effect on the other variables in the model. An interaction was then discovered between the re-categorised intervention group and cows that were fed dairy meal in the last month of gestation. The hazard risk of conception in the groups that fed leguminous shrubs (Nutrition only and Combined groups) was higher than the other groups, but this association was only seen on farms that fed dairy meal supplementation in the last month of gestation. Figure 3 demonstrates that the outcome response (conception hazard/risk) to dairy meal supplementation in the last month of gestation (right hand side of the graph) depends on the category of intervention group (different lines of the graph).

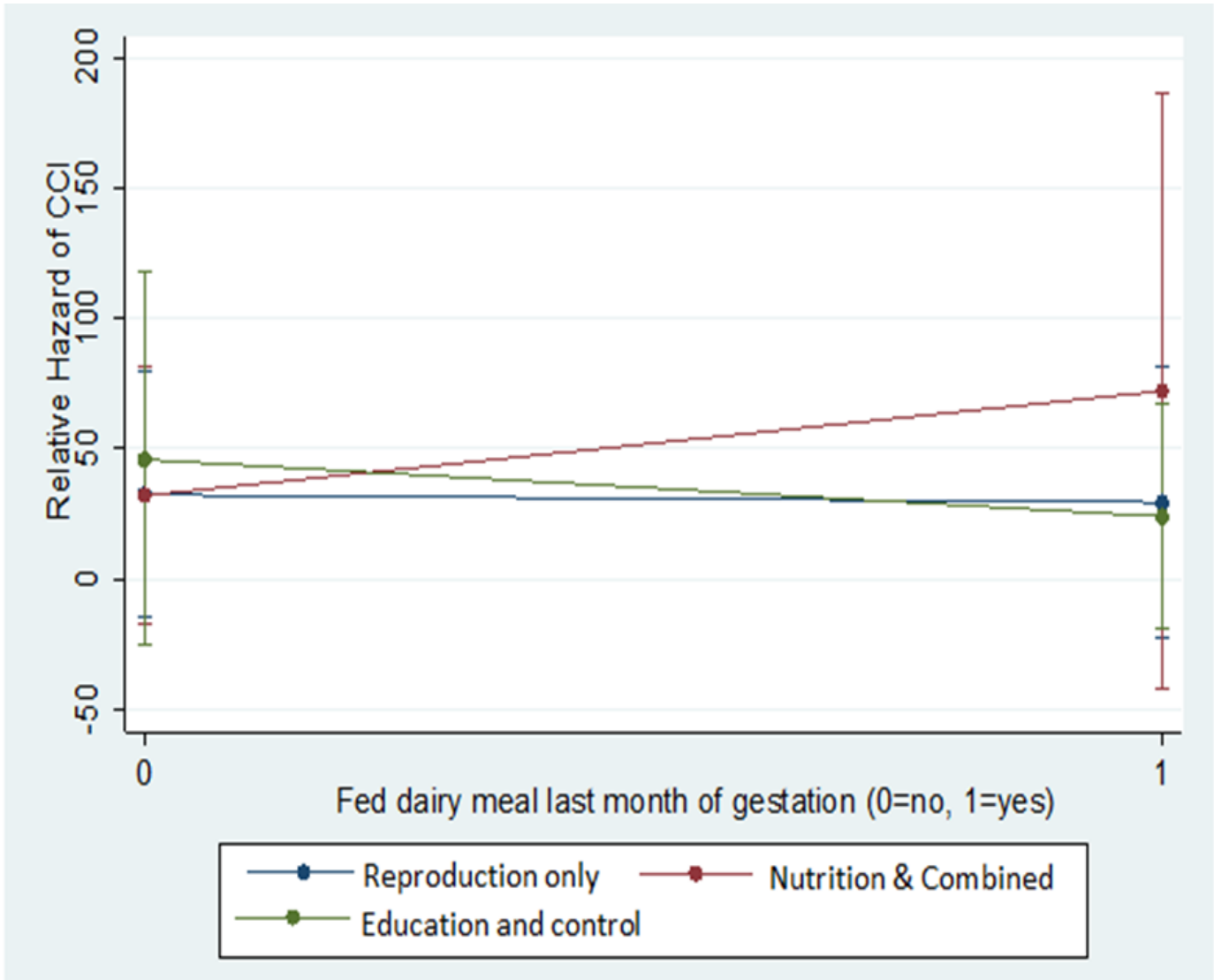

Figure 3. Interaction plot of high energy concentrate supplementation during the last month of gestation and intervention group on the hazard of conception in 191 smallholder dairy cows on 97 farms in Kenya in 2016-18

\section{Discussion}

\section{Reproductive intervention}

This is the first study in Kenya to test the effect of a reproductive program that includes education and hormone therapy to induce cows to come into heat and to help them achieve a specific set of breeding criteria meant to enhance the success of using sexed semen among semi-commercial smallholder dairy farmers. The reproduction group recorded the highest heat submission percentage at $35.5 \%$ and the control group had the lowest heat submission percentage at only $8.5 \%$. Because the trial cows were privately owned, we could only encourage farmers to submit cows in heat for service, whereas farmers would sometimes wait to breed a cow in heat because they could not currently afford the AI cost, or delay breeding to a later time when they 
perceived the probability of conception would be higher to avoid having more than one AI cost. An ANOVA test confirmed that these percentages were significantly different $(\mathrm{P}<0.05)$, demonstrating the benefits of reproduction education coupled with hormone therapy to improve heat submission percentages.

This is also the first study in Kenya to determine the conception percentage of sexed semen in various contexts of smallholder dairy cows. The study results showed that the overall conception percentages were $44.0 \%$ and $54.5 \%$ for cows and heifers (Table 1), which was higher than that reported by Norman et al., (2010) of $24 \%$ in cows and $39 \%$ in heifers in the United States. Silva et al., (2009) reported 49-63\% conception percentages in heifers and $21 \%$ in cows from a study done in California, USA. Continued and recent advances improving the fertility of sexed semen may account for some of these differences seen, along with the application of the breeding criteria recommended for farmers in our study in order to enhance the chances of conception with the sexed semen. For comparison purposes, our results found $71 \%$ and $79 \%$ of cows and heifers conceived with conventional semen, respectively.

Furthermore, this is the first study to in Kenya determine factors associated with calving-toconception interval (CCI) in smallholder dairy cows. Although the conception percentage in cows for conventional semen was higher than for sexed semen, the median CCI was lower for sexed semen than conventional semen due to the efforts of the reproductive intervention to get cows bred sooner with sexed semen, which was demonstrated by the 2.0 hazard ratio for sexed semen relative to conventional semen in the CCI survival model (Table 5). Furthermore, the cows receiving sexed semen were put through the rigorous breeding criteria that allowed good BCSs, clean uteri and better estrus observation while this was not done for animals receiving conventional semen. Some cows being inseminated with conventional semen may not have been in the optimal BCS, and could have had infected uteri, leading to a reduced hazard of conception. By optimizing the use of the stated breeding criteria for most of the cows receiving sexed semen in this study, conception percentages were likely optimised in this context. Although the descriptive statistics of this study show that the farms and cows in this study are similar to other studies in Kenya (Gitonga, 2010; Kathambi et al., 2019), this study should be replicated in another area with SDFs in Kenya or elsewhere to confirm the generalizability of the results.

Our results showed $72 \%$ and $79 \%$ conception percentages for cows and heifers, respectively, for conventional semen, whereas 44.0 and $54.5 \%$ were the conception percentages using sexed semen, respectively. However, these relative fertility parameters should be compared with caution due to differences in the contexts of the use of sexed and conventional semen in this study (i.e., the timing of the conventional semen was sometimes later in lactation than the sexed semen when sexed semen was unsuccessful twice or the DIM of the cow exceeded the sexed semen breeding criteria, when NEB would likely be reduced). Because the trial cows were privately owned, we could only encourage farmers to utilise the sexed semen through the price subsidy (same cost as conventional semen).

Sexed semen is often recommended for use on heifers because a heifer uterus is usually more fertile (i.e. less likely to have a uterine infection) than a cow uterus, and heifers are genetically superior, on average, compared with older cows of previous generations (Garner \& Seidel, 2008). However, heifers with delayed puberty were a common finding in our study, and a related study looking at calves and heifers in our study area commonly found open heifers over 36 months old (Makau et al., 2018a ). In that study, the average daily gain for heifers between 15-36 months was $0.364 \mathrm{~kg}$. Therefore, only well-fed heifers meeting the proposed breeding criteria should be considered for sexed semen usage on SDFs in this area of Kenya and elsewhere.

Conception percentages achieved through sexed semen have been known to vary significantly with a number of on-farm factors, such as parity, age, body condition, sire selection and accuracy of estrus detection (Healy et al., 2013). Our study showed a rise in the probability of sexed semen conception with rising BCS, both as the BCS prior to service (Figure 2) and as the average BCS 
during the breeding period in our final model (Table 4). There were substantial gains in conception in cows with BCS of 2 compared to 1.5 and 1 , and then a more gradual rise in sexed semen conception observed when BCSs were over 2.0 (Figure 2). To achieve a 50\% probability of conception with sexed semen, cows needed a BCS of at least 2.5, and this observation justified our cut-off point of 2.25 for sexed semen use in our Kenyan SDF context. Resource-constrained smallholder farmers should use BCS of at least 2.5 before considering the purchase of sexed semen for a cow due to its lower relative fertility $(75-80 \%$ compared to that of unsorted semen, based on data generated in the United States) and substantial cost (DeJarnette et al., 2011).

Low conception percentages with sexed semen have also been associated with reduced quality of the sexed semen following the sexing process and other factors that affect conception percentage with artificial insemination such as improper heat detection, inseminator's technique, infection of the reproductive system, heat stress, and other diseases that affect the reproductive system (Donovan et al., 2003). Increasing sperm numbers from the recommended two million sperm cells to ten million sperm cells in a straw of sexed semen did not seem to improve the conception percentages seen elsewhere (DeJarnette et al., 2011; Seidel \& Schenk, 2008). In our study, sperm concentrations of 1.2 million per straw were used, but it is unclear whether this lower sperm number impacted the conception percentages.

\section{Factors associated with hazard of conception}

In our study, cows on farms where the farmers had received some form of dairy-related training had increased hazard of conception compared to cows on farms where farmers reported not having any dairy-related training. In this area of Kenya, farmer training has taken the form of group-targeted teachings organised by dairyrelated non-governmental organizations, farmer seminars and workshops from selected individuals on selected topics, as well as farm visits to other better producing farms and dairy cooperatives in this and other regions to see better management procedures in practice. In general, smallholder dairy farmers in Africa have experience in rearing animals, but they are continuing to rely on traditional husbandry practices on their exotic-cross cows, such as using bulls instead of AI for reproduction, feeding poor quality diets, and keeping non-pregnant cows on the farm as long as they produce milk, which are likely contributing to low milk productivity and reproduction (Vaarst et al., 2007). In a study that included farmer training methods in Pakistan, substantial adoption rates of new techniques by the smallholder dairy farmers and their families were observed (Warriach et al., 2018). In that study, farmers who adopted the recommendations observed a wide range of positive impacts, including improved reproductive parameters.

The hazard of conception in cows with hormonally induced heats was 0.6 times the hazard of those cows coming in heat spontaneously. Hormonal treatments are quick and easy to implement, but they may not be very effective in circumstances of marginal nutrition on SDF in LICs. Furthermore, routine use of hormones may diminish the need to tackle root causes of poor fertility, and the root causes may have productivity, health and welfare implications for the herd (Perry, 2005). Hormone use in our study was associated with lower hazard of conception, and this could be due to the fact that cows that received the GnRH were those that had small, smooth ovaries that were over $1.5 \mathrm{~cm}$ in diameter (representing a cycling ovary without a CL that would respond to PG or a dominant follicle) and had not been seen in heat. Similarly, there may have been an underlying problem of estrus detection among the farmers, especially in cows that had a functional CL, requiring the use of prostaglandin $\mathrm{F} 2 \mathrm{a}$ with instructions on when to observe for heat signs to help resolve this problem. Furthermore, farmers may have been more inclined to inseminate cows regardless of signs of heat because the hormone was given and there was an expectation that they should be inseminated. Nevertheless, if farmers are having difficulty with cows not cycling or showing heat signs, hormone therapy is likely to be helpful since conception percentages obtained with hormone use in this study were considered good $(57-79 \%)$.

In an interaction term, supplementing cows with some high energy concentrates during the last 
month of gestation was associated with a higher hazard of conception, but only when farmers fed leguminous shrubs (Figure 3). It has been demonstrated that failure to provide enhanced feeding (e.g. concentrate) to dairy cows during the 3-4 weeks prior to calving can lead to loss of body condition as the fetus rapidly grows and the udder fills with colostrum, leading to NEB before calving, and then worse NEB after calving, leading to a longer anestrus period before normal reproduction function can be regained (Block, 2010). However, the additional protein provided from the leguminous shrubs being fed appears to have provided a synergistic effect on CCI with the concentrate being fed pre-partum (Figure 3). Providing sufficient protein is a costly proposition for impoverished smallholder dairy farmers in Kenya, making protein deficiencies common (Makau et al., 2018a; Wambugu et al., 2006). Indeed, the figure suggests that the hazard of conception when feeding high protein leguminous shrubs did not have much benefit unless concentrate was fed pre-partum, confirming that both were important to good reproduction in the study cows. The two study groups receiving leguminous shrubs had also received extensive training on cow nutrition; therefore, it could be that the training is also partly responsible for the lower CCI. Transition cow feeding is not widely known and/or practised among smallholder dairy farmers in this area of Kenya (23\% of cows in our study population) but should be recommended by extension officers. The very long CCI recorded in the study demonstrates a need for enhanced management, focused on both nutrition and reproduction.

\section{Study limitations}

The biggest challenge during the study was the very high turnover of animals. Cows in this area are deemed as assets that could be easily liquidated in situations where there is need of money, such as school fees or in cases of death or disease in the family or need of animals given out as a form of dowry. This high turnover led to study animals being lost to follow-up at different stages of the study, limiting out study population and ability to find additional significant factors of CCI in the survival analyses. The number of farms was limited by logistical and budgetary constraints, while the duration of the study was limited to a 17-month data collection period.

The study period posed another challenge, related to changes in weather patterns. Prolonged drought was experienced in 2017 due to lower-than -expected rainfall in late February to early May. Therefore, farmers were faced with major challenges of feeding appropriate quality and quantities of forage to the cows. Body conditions in cows dropped during this time and it took a while before the animals recovered BCS to pre-drought levels. Even though the farmers have been taught how to conserve fodder, especially through silage-making, some farmers indicated that it was costly to make silage since they did not own a chopping machine, so they had to hire one and also hire the labour to pack the silage. As an intervention of the NDFCS, more chopping machines were procured and rented out to the farmers at affordable prices, but only after the life of the project.

Accurate data collection in the smallholder dairy setting was also challenging; farmers had trouble recalling the reproductive events of the past calving and most farmers did not keep proper records. Therefore, the farmers were supplied with writing books that were labelled to show them when and how to record the dates of heat, service, drying off and parturition for each cow on the farm. Some of the farmers were still missing this information due to illiteracy or poor compliance, while other farmers misplaced the books. Farmers were also advised to carefully store the inseminators' records, and to provide them to the research team on the next visit for data collection. An ultrasound machine would have been helpful to clarify ovarian and uterine findings on rectal palpation, but it was not available for practical and budgetary reasons. Future research on this topic would benefit from an ultrasound machine.

A number of other challenges led to fewer or delayed services with sexed semen than expected among these semi-commercial smallholder dairy farms where decisions are made in the best interests of the farm, not the research project. First, despite much education, some farmers still had a problem correctly detecting heat or reporting it in good time for service. Also, 
farmers sometimes chose to delay breeding their cows for varying reasons, such as lack of funds or plans to skip a heat or two before service due to perceptions of higher conception with the delay. Plans to sell a cow also led to decisions not to breed a cow. Delays in breeding could have contributed to the higher-than -expected conception percentages, particularly for the conventional semen. Therefore, identical preinsemination treatment on these semicommercial farms was not possible. However, the "real-world" study population provides excellent representativeness of the study results in the smallholder dairy farm context, something a research herd cannot provide.

Secondly, an AI technician employed by the NDFCS was utilised to conduct the AI services on credit to the NDFCS-member farmers in the study. However, there were other AI providers in the area who were sometimes blood relatives to some of the study farmers. These farmers would sometimes feel obliged to use their relatives for AI rather than the NDFCS AI technician who was the only one who was supplied with the subsidised sexed semen for NDFCS member farmers in the study.

Finally, because the NDFCS AI technician was the only one doing the AIs with the sexed semen for the project, the technician was unavailable over some weekends, leading to some cows in heat not being bred or leading to farmers seeking AI services elsewhere, but then not using the project's sexed semen. Future research projects should engage a larger number of smallholder farms and/or multiple AI technicians to ensure a higher sample size of cows bred using sexed semen.

Contamination of the control groups was expected in this study because it has been documented elsewhere among smallholder dairy farmers in Kenya (Kathambi et al., 2019; Makau et al., 2018b). There is a strong desire among the farmers to improve their management, the farmers are often quite willing to share what they know with their neighbours, and the farms are small and therefore close together, making communication between farms relatively easy. Contamination could partly explain the higher conception percentages of the control groups compared to the reproductive group. However, these conception percentages in control groups were based on smaller numbers of cows inseminated with sexed semen than other groups; therefore, these percentages may be susceptible to selection or confounding bias. Lack of blinding may have also biased the study results but due to the study design, blinding was not possible.

While it was hypothesised that nutritional factors would likely be some of the main factors associated with $\mathrm{CCI}$, the large variability of the cows' diets (often changing with seasonal availability of different forages on the farm) and limited budget did not allow us to determine amounts and concentrations of nutrient levels of what was fed. Future research would benefit from quantification of the amounts and concentrations of nutrient levels of feeds consumed.

Recovery from endometritis was reported in 23 of the 30 diagnosed cows $(77 \%)$ in response to cephapirin treatment, which is similar to that found in Canada (Leblanc et al., 2002). However, this trial was not designed to determine the treatment effect of cephapirin compared to a positive (prostaglandin treatment) or negative control in a SDF context. In future research, a randomised controlled trial on SDFs should be conducted to provide trial data for animal health professionals to determine the efficacy of cephapirin and/or prostaglandin as reliable treatments for endometritis in the LIC context.

\section{Conclusions}

The GnRH and PG hormones utilised in this study, along with the reproductive education supplied, were observed to have a positive effect on the proportion of cattle to be serviced on SDFs in Kenya, and therefore should be considered to augment reproductive management. With the good conception percentages, we obtained in our study in cows pre-screened for breeding criteria, sexed semen can have a role in providing much needed replacement heifers in the smallholder dairy setting in LICs. However, an adequate body condition score and clear mucous in cows in heat should be attained before sexed semen is utilised to ensure good conception percentages. 
Feeding cows concentrate during the month prior to calving and utilizing high protein forages, such as drought-resistant leguminous shrubs, were associated with a higher hazard of conception, and therefore should be promoted to optimise CCI. However, with the sexed semen conception percentage equal to approximately $50 \%$, smallholder farmers should be prepared for two breedings per pregnancy, on average. Animal health personnel and extension officers should provide smallholder dairy farmers with additional training aimed at improving nutritional and reproductive performance, especially drought-resistant leguminous shrubs, and feeding cows concentrate during the month prior to calving should be provided to improve BCS and CCI.

\section{References}

Ashworth, C.J., L.M. Toma, and M.G. Hunter., (2009). Nutritional effects on oocyte and embryo development in mammals: Implications for reproductive efficiency and environmental sustainability. Philosophical Transactions of the Royal Society B: Biological Sciences $364 \quad$ (1534): $\quad$ 3351-61. doi:10.1098/rstb.2009.0184.

Beam, S.W, and W.R. Butler., (1999) Effects of energy balance on follicular development and first ovulation in postpartum dairy cows. Journal of Reproduction and Fertility. Supplement 54: 411-24. http://www.ncbi.nlm.nih.gov/pubmed/1 0692872.

Bebe, B.O., (2004). Effects of feeding systems and breed of cattle on reproductive performance and milk production on smallholder farms. Uganda Journal of Agricultural Sciences, 9 (1 pt2): 558-63. www.ajol.info/index.php/ujas/article/vie wFile/135521/125028.

Block, E., (2010). Transition cow research - What makes sense today? High Plains Dairy Conference, 75-98.

Butler, W.R., (2000). Nutritional interactions with reproductive performance in dairy cattle. Animal Reproduction Science 60-61 (July): $449-57$.

\section{Acknowledgements}

We are grateful to the primary funding program for this research, the Canadian Queen Elizabeth II Diamond Jubilee Scholarships (QES) which are managed through a unique partnership of Universities Canada, the Rideau Hall Foundation (RHF), Community Foundations of Canada (CFC) and Canadian universities. This program is made possible with financial support from the Government of Canada, provincial governments, and the private sector. We also acknowledge Farmers Helping Farmers, the Naari Dairy Farmers Cooperative Society and summer students Kelsie Goodick, Ali Frye, Ren Chamberlain and Julia Kenny.

http:/ /www.ncbi.nlm.nih.gov/pubmed/1 0844215.

Centurión-castro, F, J. Orihuela-porcayo, R.J. Aké-lópez, J.G. Magaña-monforte, R.C. Montes-Pérez, and J.C. Segura-Correa., (2013). Effect of body condition score on estrus and ovarian function characteristics of synchronized beef-master cows. Tropical and Subtropical Agroecosystems, 16 (2013): 193 - 199.

Chagas, L.M., J.J. Bass, D. Blache, C.R. Burke, J.K. Kay, D.R. Lindsay, M.C. Lucy., (2007). Invited review: New perspectives on the roles of nutrition and metabolic priorities in the subfertility of high-producing dairy cows. Journal of Dairy Science 90 (9): 4022-32. doi:10.3168/jds.2006-852.

Colazo, M.G, and R.J. Mapletoft., (2014). A review of current timed-AI (TAI) programs for beef and dairy cattle. The Canadian Veterinary Journal -La Revue Veterinaire Canadienne $55 \quad$ (8):772-80. http://www.ncbi.nlm.nih.gov/pubmed/2 5082993.

DeJarnette, J.M., M.A. Leach, R.L. Nebel, C.E. Marshall, C.R. McCleary, and J.F. Moreno., (2011). Effects of sex-sorting and sperm dosage on conception rates of Holstein heifers: Is comparable fertility of sex-sorted and conventional semen plausible? Journal of Dairy Science 94 (7): 3477-83. 
doi:10.3168/jds.2011-4214.

Donovan, G.A., F.L. Bennett, and F.S. Springer., (2003). Factors associated with first service conception in artificially inseminated nulliparous Holstein heifers. Theriogenology $60 \quad$ (1): $67-75$. http://www.ncbi.nlm.nih.gov/pubmed/1 2620581.

Ferguson, J.D., G. Azzaro, and G. Licitra., (2006). Body condition assessment using digital images. Journal of Dairy Science 89 (10): 3833-41. doi:10.3168/jds.S00220302(06)72425-0.

Ferguson, J.D, D.T Galligan, and N.Thomsen., (1994). Principal descriptors of body condition score in Holstein cows. Journal of Dairy Science 77 (9). Elsevier: 2695-2703. doi:10.3168/jds.S0022-0302(94)77212-X.

Garner, D.L, and G.E. Seidel., (2008). History of commercializing sexed semen for cattle. Theriogenology 69 (7): $886-95$. doi:10.1016/j.theriogenology.2008.01.006.

Gitonga P. N., (2010). Postpartum reproductive performance of dairy cows in medium and large scale farms in Kiambu and Nakuru Districts of Kenya. https://www.uonbi.ac.ke/.../files/dr._pa uline_gitonga_msc._thesis.pdf.pdf.

Healy, A.A., J.K. House, and P.C. Thomson., (2013). Artificial insemination field data on the use of sexed and conventional semen in nulliparous Holstein heifers. Journal of Dairy Science $\quad 96 \quad$ (3): $\quad$ 1905-14. doi:10.3168/jds.2012-5465.

Hertz-Picciotto I and B. Rockhill., (1997). Validity and efficiency of approximation methods for tied survival times in Cox regression. Biometrics 53: 1151-6. doi.org/10.2307/2533573.

Islam, R., (2011). Synchronization of estrus in cattle: A review. Veterinary World 4 (3): 13641. doi:10.5455/vetworld.2011.136-141.

Jaetzold, R., and H. Schmidt., (2006). Farm Management Handbook of Kenya. Natural Conditions and Farm Management Information. Vol. II. Kenya Minstry of Agriculture

Joezy-Shekalgorabi, S., A. Maghsoudi, and M.R.
Mansourian., (2017). Reproductive performance of sexed versus conventional semen in Holstein heifers in various semiarid regions of Iran. Italian Journal of Animal Science $\quad 16 \quad$ (4): $666-72$. doi:10.1080/1828051X.2017.1321473.

Kathambi, E.K., J.A. VanLeeuwen, G.K.Gitau, C. Revie., (2019). Assessment of farmers' compliance in implementing recommended cow comfort changes and their effects on lying time, stall and cow cleanliness within smallholder dairy farms in Kenya. Preventive Veterinary Medicine 172:104784 https://doi.org/10.1016/j.prevetmed.2019. $\underline{104784}$

Khorshidi, R., M. D. MacNeil, J.J. Crowley, M.M. Scholtz, A. Theunissen and G.S. Plastow., (2017). Evaluating breed complementarity and sexed semen with maternal use of Afrikaner germplasm. Agricultural Sciences 08 (07): 507-17. doi:10.4236/as.2017.87038.

Kurykin, J., (2017). Sex-sorted semen: Efficiency of insemination and opportunities to increase outcome of pregnancies in dairy and beef cattle. A review. Veterinary Medicine Zootechnology 75: 97. https://vetzoo.lsmuni.lt/data/vols/2017/ 75/pdf/kurykin1.pdf.

LeBlanc S.I., T.F. Duffield, K.E. Leslie, K.G. Bateman, G.P. Keefe, J.S. Walton, W.H. Johnson., (2002) The effect of treatment of clinical endometritis on reproductive performance in dairy cows. Journal of Dairy Science. 85(9):2237-49.

Makau, D.N, J.A. VanLeeuwen, G.K. Gitau, J. Muraya, S.L. McKenna, C. Walton, and J.J. Wichtel., (2018a). Animal and management factors associated with weight gain in dairy calves and heifers on smallholder dairy farms in Kenya. Preventive Veterinary Medicine. 161:60-68. doi:10.1016/J.PREVETMED.2018.10.017.

Makau, D.N, J.A. VanLeeuwen, G.K. Gitau, J. Muraya, S.L. McKenna, C. Walton, and J.J. Wichtel. (2018b). Effectiveness of using cellphone technology as a dairy management training tool for smallholder dairy farms in Kenya. Livestock Research and Rural Development. 30:195. Retrieved May 
11,

2020 ,

from

http://www.lrrd.org/lrrd30/11/dennm30 195.html

Makau, D.N, J.A. VanLeeuwen, G.K. Gitau, S.L. McKenna, C. Walton, J. Muraya, and J.J. Wichtel. (2020) Randomized controlled trial on the effect of Calliandra and Sesbania supplementation on milk production in dairy cattle on smallholder dairy farms in Kenya. Veterinary Medicine International. 3262370:1-15. doi.org/10.1155/2020/3262370

Norman, H.D., J.L. Hutchison, and R.H. Miller., (2010). Use of sexed semen and its effect on conception rate, calf sex, dystocia, and stillbirth of Holsteins in the United States. Journal of Dairy Science 93 (8): 3880-90. doi:10.3168/jds.2009-2781.

Othieno, J., (2016). Want calf of a specific sex? Try this method: Kenya - The Standard. Standard Digital. https://www.standardmedia.co.ke/busin ess/article/2000204786/want-calf-of-aspecific-sex-try-this-method.

Perry, G., (2005). Factors that influence fertility in natural and synchronized breeding programs. In Proceedings, Applied Reproductive Strategies in Beef Cattle, 127-48. Reno, Nevada. https://www.researchgate.net/publicatio n/267549540_factors_that_influence_fertili ty_in_synchronized_breeding_programs_a i_or_natural_service.

Richards S., Vanleeuwen J., Peter S. G., Wichtel J., Kamunde C., Uehlinger F. and Gitau G., (2019) Impact of mineral feeding on reproductive efficiency on smallholder dairy farms in Kenya. Livestock Research for Rural Development. Volume 31, Article \#80. Retrieved June 18, 2021， from http://www.lrrd.org/lrrd31/6/srich31080 .html

Sá Filho, M.F., H. Ayres, R.M. Ferreira, M. Nichi, M. Fosado, E.P. Campos Filho, and P.S. Baruselli., (2010). Strategies to improve pregnancy per insemination using sexsorted semen in dairy heifers detected in estrus. Theriogenology 74 (9): 1636-42. doi:10.1016/j.theriogenology.2010.06.036.
Schenk, J.L., D.G. Cran, R.W. Everett, and G.E. Seidel., (2009). Pregnancy rates in heifers and cows with cryopreserved sexed sperm: effects of sperm numbers per inseminate, sorting pressure and sperm storage before sorting. Theriogenology 71 (5): 717-28. doi:10.1016/j.theriogenology.2008.08.016.

Seidel, G.E., and J.L. Schenk., (2008). Pregnancy rates in cattle with cryopreserved sexed sperm: Effects of sperm numbers per inseminate and site of sperm deposition. Animal Reproduction Science 105 (1-2): 12938. doi:10.1016/j.anireprosci.2007.11.015.

Seidel, G.E., J.L. Schenk, L.A. Herickhoff, S.P. Doyle, Z. Brink, R.D. Green, and D.G. Cran., (1999). Insemination of heifers with sexed sperm. Theriogenology 52 (8). Elsevier: 140720. doi:10.1016/S0093-691X(99)00226-5.

Silva, C.J, S. Henderson, and S. L. Obispo., (2009). Conception rates of sexed semen in lactating cows. https://digitalcommons.calpoly.edu/cgi/ viewcontent.cgi?referer=https://www.goo gle.ca/ \&httpsredir $=1 \&$ article $=1019 \&$ conte $\mathrm{xt}=\mathrm{d}$ scisp.

Vaarst, M., D. K. Byarugaba, J. Nakavuma, and C. Laker., (2007). Participatory livestock farmer training for improvement of animal health in rural and peri-urban smallholder dairy herds in Jinja, Uganda. Tropical Animal Health and Production 39 (1): 1-11. doi:10.1007/s11250-006-4439-8.

Wambugu, C., S. Franzel, J. Cordero, and J. Stewart., (2006). Fodder shrubs for dairy farmers in East Africa: Making extension decisions and putting them into practice. World Agroforestry Centre, Nairobi, Kenya; Oxford Forestry Institute, Oxford, U.K. $172 \mathrm{Pp}$, 170.

Wang Y., Huo P., Sun Y., Zhang Y., (2019). Effects of Body Condition Score Changes During Peripartum on the Postpartum Health and Production Performance of Primiparous Dairy Cows. Animals 9(12):1159. doi: 10.3390/ani9121159.

Warriach, H.M, P.C. Wynn, M. Ishaq, S. Arif, A. Bhatti, S. Latif and A. Kumbher., (2018). Impacts of improved extension. services on awareness, knowledge, adoption rates and 
perceived benefits of smallholder dairy farmers in Pakistan. Animal Production Science - https:// doi.org/10.1071/ AN17849 